\title{
Genetic polymorphisms of Wnt/ $\beta$-catenin pathway genes are associated with the efficacy and toxicities of radiotherapy in patients with nasopharyngeal carcinoma
}

\author{
Jingjing Yư ${ }^{1}$, Yuling Huang ${ }^{2}$, Lijuan Liư ${ }^{3}$, Jing Wang ${ }^{2}$ Jiye Yin ${ }^{4}$, Lihua Huang ${ }^{5}$, \\ Shaojun Chen ${ }^{6}$, Jingao Li ${ }^{2}$, Hong Yuan ${ }^{1}$, Guoping Yang ${ }^{1}$, Wenyu Liư ${ }^{7}$, Hai Wang ${ }^{8}$, \\ Qi Pei ${ }^{1}$, Chengxian Guo ${ }^{1}$ \\ ${ }^{1}$ Center of Clinical Pharmacology, The Third Xiangya Hospital, Central South University, Changsha, Hunan 410013, China \\ ${ }^{2}$ Department of Radiation Oncology, Jiangxi Province Tumor Hospital, Nanchang, Jiangxi 330029, China \\ ${ }^{3}$ Department of Pharmacy, Jiangxi Cancer Hospital, Nanchang 330029, China \\ ${ }^{4}$ Department of Clinical Pharmacology, Xiangya Hospital, Central South University, Changsha, Hunan 410008, China \\ ${ }^{5}$ Center for Medical Experiments, The Third Xiangya Hospital, Central South University, Changsha, Hunan 410013, China \\ ${ }^{6}$ Department of Oncology, Fourth Affiliated Hospital, Guangxi Medical University, Liuzhou, Guangxi 545005, China \\ ${ }^{7}$ College of Pharmacy, Central South University, Changsha, Hunan 410008, China \\ ${ }^{8}$ Xiangya Medical College, Central South University, Changsha, Hunan 410008, China \\ Correspondence to: Chengxian Guo, email: gchxyy@163.com \\ Keywords: nasopharyngeal carcinoma (NPC), Wnt/ $\beta$-catenin pathway, single nucleotide polymorphism (SNP), curative efficacy, \\ toxic reaction
}

Received: May 22, 2016

Accepted: October 14, 2016

Published: October 19, 2016

\section{ABSTRACT}

Radiotherapy (RT) is the normative therapeutic treatment for primary nasopharyngeal carcinoma (NPC). Single nucleotide polymorphisms (SNPs) of genes in Wnt/ $\beta$-catenin pathway are correlated to the development, prognosis, and treatment benefit of various cancers. However, it has not been established whether SNPs of Wnt/ $\beta$-catenin pathway are associated with nasopharyngeal tumorigenesis and the efficacy of RT in NPC patients. Therefore, in this study, we aimed to investigate the nine potentially functional SNPs of four genes in the Wnt/ $\beta$-catenin pathway and genotyped these in 188 NPC patients treated with RT. To achieve this goal, associations between these SNPs and the RT's curative efficacy, as well as acute radiation-induced toxic reaction were determined by multifactorial logistic regression. We observed that catenin beta 1 gene (CTNNB1) rs1880481 and rs3864004, and glycogen synthase kinase 3 beta gene (GSK3 $\beta$ ) rs3755557 polymorphisms were significantly associated with poorer efficacy of RT in NPC patients. Moreover, GSK3 $\beta$ rs375557 and adenomatous polyposis coli gene (APC) rs454886 polymorphisms were correlated with acute grade 3-4 radiation-induced dermatitis and oral mucositis, respectively. In conclusion, this study suggests that gene polymorphisms of Wnt/ $\beta$-catenin may be novel prognostic factors for NPC patients treated with RT.

\section{INTRODUCTION}

Nasopharyngeal carcinoma (NPC) is a common malignancy with an obvious ethnic and geographical distributed imbalance in the incidence rate [1]. The annual incidence of NPC in United States is only 0.7 per 100,000, while in southern China it is much greater, with annual rates between 15 and 30 cases per 100,000 in Hong Kong alone [1,2]. Radiotherapy (RT) is the normative treatment choice for primary NPC patients $[2,3]$. Despite advances in RT techniques and development of other efficacious modalities such as surgery and chemotherapy, patients with NPC still have a poor prognosis due to a range of adverse effects and drug resistance [4]. With the development of radiogenomics, a number of studies have demonstrated that dysregulation of gene expression may be useful as independent factors for the curative efficacy as well as the toxicity of RT (with or without concurrent chemotherapy) in NPC patients [5-9]. Moreover, single nucleotide polymorphisms (SNPs) of genes have been 
validated to be involved in the development, progression and treatment benefit of human cancers [10-12]. For example, one study identified that SNPs of interferon regulatory factor-4 (IRF4) were associated with melanoma development [13]. Another study validated that SNPs of F-box and WD repeat domain containing 7 (FBW7) could be the predictive factor for paclitaxel plus cisplatin chemotherapy in patients with advanced esophageal squamous cell carcinoma [14]. Moreover, SNP of WWOX was found to represent a major predictive factor in gemcitabine-treated pancreatic cancer [15]. Similarly, Li et al. reported that NPC patients with the XRCC1 399Arg/Gln genotype were more likely to experience severe acute radiation-induced dermatitis and oral mucositis [16]. Additionally, it has been reported that SNPs of matrix metalloproteinase-1(MMP-1) promoter were associated with risk of radiation-induced lung injury in lung cancer patients with radiotherapy treatment [17].

The Wnt signaling pathway plays a vital role in many fundamental physiological processes [18]. Wnt ligands can direct these processes via a number of signaling pathways. The Wnt/ $\beta$-catenin pathway, including many components, such as $\beta$-catenin, adenomatosis polyposis coli (APC), axin, and glycogen synthase kinase 3 beta (GSK3 $\beta$ ), is commonly considered to be the canonical Wnt pathway [19]. The central role of $\mathrm{Wnt} / \beta$-catenin pathway is $\beta$-catenin, which forms a destruction complex with APC, axin, and GSK3 $\beta$, leading to phosphorylation and subsequent degradation in the absence of Wnt signaling. In the presence of Wnt signaling, $\beta$-catenin is uncoupled from the complex and transfers into the cell nucleus, and then activates target genes [20]. Several studies have demonstrated that some mutations, especially SNPs of $\mathrm{Wnt} / \beta$-catenin pathway genes, are correlated to the occurrence, development and prognosis of various cancers including NPC [21-26]. Jiang et al. found that high expression of Wnt 2 was strongly associated with poor clinical outcomes in patients with pancreatic cancer [27]. Furthermore, other studies have found the association between the dysregulation of Wnt/ $\beta$-catenin pathway and RT in certain cancers [28-30]. For example, Hai et al. explored the impact of transient activation of $\mathrm{Wnt} / \beta$-catenin signaling on radiation damage to salivary glands in a preclinical model [30]. Their results suggested that concurrent transient activation of the $\mathrm{Wnt} / \beta$-catenin pathway may reduce the risk of radiationinduced salivary gland dysfunction [30]. However, the relationship between SNPs of Wnt/ $\beta$-catenin pathway genes and the efficacy of, or the toxic reactions to, RT in NPC patients has not been elucidated.

According to previously published studies [31-38], 9 potentially functional SNPs of 4 key genes in the Wnt/ $\beta$-catenin pathway, including catenin beta 1 (CTNNB1, encoding $\beta$-catenin) rs4135385, rs1880481, rs3864004; GSK3 $\beta$ rs375557; APC rs454886, rs3777860; Wnt2 rs2896218, rs10487362, and rs6947329, were selected in our current study. The purpose of this study was to establish the relationship, if any, between these 9 SNPs of the $\mathrm{Wnt} / \beta$-catenin pathway genes and the efficacy of RT, as well as acute radiation-induced toxic reaction in NPC patients. We also aimed to find novel genetic markers for predicting NPC patients' response to RT.

\section{RESULTS}

\section{Clinical characteristics, patients' responses to RT and genotyping}

The studied cohort of 188 patients included 130 males and 58 females, with a mean age of 50.7 (ranging from 14 to 81 ) years old. Serum EBV-DNA of 127 patients $(67.6 \%)$ were found to be positive. 150 patients $(79.8 \%)$ were treated with chemotherapy, while the remaining $38(20.2 \%)$ were treated with radiotherapy alone. The general clinical characteristics and outcomes, including curative efficacy and toxic reactions after RT, of the 188 patients with NPC are summarized in Table 1. Although some data were missing, we included 155 patients for the curative efficacy of RT on the lymph node after treatment, 135 patients for the curative efficacy of RT on the primary tumor 3 months after treatment, and 114 patients for the curative efficacy of RT on the lymph node 3 months after treatment. Overall, 19.7\% of the patients did not get complete remission (CR) for their primary tumors immediately after RT, while $8.1 \%$ failed to get CR for their primary tumors 3 months after RT. Further, $14.2 \%$ of the patients did not get CR for their lymph nodes immediately after RT, while $10.5 \%$ did not do so 3 months after RT. Regarding toxic reactions, in the 188 patients, $16(8.5 \%)$ experienced grade $3-4$ acute radiationinduced dermatitis, $89(47.3 \%)$ presented with grade 3-4 acute radiation-induced oral mucositisand, and 44 (23.4\%) suffered from grade 3-4 acute radiation-induced myelosuppression. The results of genotypes of 9 SNPs in the $A P C, W n t 2, C T N N B 1$ and GSK3 $\beta$ genes of the 188 patients are shown in Table 2. For one of the 188 patients, we did not obtain the genotype of Wnt 2 rs6947329, and for another patient, we did not obtain the genotypes of $A P C$ rs3777860 and CTNNB1 rs3864004. All SNPs were analyzed by Hardy-Weinberg equilibrium. However, the genotype distributions of rs4135385 and rs3777860 polymorphisms were not in accordance with the HardyWeinberg equilibrium and excluded in further analysis. All the minor allele frequencies (MAFs) of the residual 7 SNPs were $>10 \%$.

\section{Association between clinical factors and responses to $\mathrm{RT}$ in NPC patients}

All the clinical factors screened out using the chi-square test as covariates in multivariate logistic regression are listed in Supplementary Tables S1 and S2. We found 
Gender

male

female

Age

mean $\pm \mathrm{SD}$ (range)

$\leq 50$

$>50$

BMI

$\leq 24.0$

$>24.0$

Family history

Yes

No

Tumor classification

$\mathrm{T}_{1}-\mathrm{T}_{2}$

$\mathrm{T}_{3}-\mathrm{T}_{4}$

Lymph node metastasis

$\mathrm{N}_{0}-\mathrm{N}_{1}$

$\mathrm{N}_{2}-\mathrm{N}_{3}$

Distant metastasis

M0

M1

Clinical stage

I-II

III-IV

EBV-DNA

Positive

Negative

Smoking

Yes

No

Drinking

Yes

No

Chemotherapy

No

Yes

Curative efficacy(Non-CR)

Primary tumor - after RT

Primary tumor -3 months after RT

lymph node - after RT

lymph node -3 months after RT

Grade 3-4 radiation- induced toxic reactions

Dermatitis

Oral mucositis

Myelosuppression
$130(69.1 \%)$

$58(30.9 \%)$

$50.7 \pm 11.8(14-81)$

$90(47.9 \%)$

$98(52.1 \%)$

$123(65.4 \%)$

$65(34.6)$

$25(13.3 \%)$

$163(86.7 \%)$

$51(27.1 \%)$

$137(72.9 \%)$

$93(49.5 \%)$

95 (50.5\%)

$182(96.8 \%)$

$6(3.2 \%)$

$26(13.8 \%)$

$162(86.2 \%)$

$127(67.6 \%)$

61 (32.4\%)

$86(45.7 \%)$

$102(54.3 \%)$

$47(25.0 \%)$

$141(75.0 \%)$

$38(20.2 \%)$

$150(79.8 \%)$

37 (19.7\%)

$11(8.1 \%)$

$22(14.2 \%)$

$12(10.5 \%)$

$16(8.5 \%)$

$89(47.3 \%)$

$44(23.4 \%)$

Abbreviations: RT, radiotherapy; BMI, body mass index; CR, complete remission. 
Table 2: Genotype distribution and MAF of 9 SNPs in $A P C, W N T 2, C T N N B 1$ and $G S K 3 \beta$ genes

\begin{tabular}{cccccc}
\hline Gene & Polymorphic site & $\begin{array}{c}\text { Alleles } \\
\text { (wild/mutant) }\end{array}$ & $\begin{array}{c}\text { Genotype } \\
\text { distribution }\end{array}$ & HWE & MAF \\
\hline$W N T 2$ & rs10487362 & $\mathrm{G} / \mathrm{A}$ & $54 / 91 / 43$ & 0.695 & 0.47 \\
$W N T 2$ & $\mathrm{r} 2896218$ & $\mathrm{~A} / \mathrm{G}$ & $91 / 87 / 10$ & 0.061 & 0.28 \\
$W N T 2$ & $\mathrm{rs} 6947329$ & $\mathrm{~T} / \mathrm{C}$ & $55 / 84 / 48$ & 0.170 & 0.48 \\
$A P C$ & $\mathrm{r} 3777860$ & $\mathrm{G} / \mathrm{A}$ & $91 / 70 / 26$ & $\mathbf{0 . 0 4 2}$ & 0.33 \\
$A P C$ & $\mathrm{rs} 454886$ & $\mathrm{G} / \mathrm{A}$ & $70 / 92 / 26$ & 0.627 & 0.38 \\
$C T N N B 1$ & $\mathrm{rs} 4135385$ & $\mathrm{G} / \mathrm{A}$ & $138 / 5 / 45$ & $<\mathbf{0 . 0 0 1}$ & 0.25 \\
$C T N N B 1$ & $\mathrm{r} 1880481$ & $\mathrm{C} / \mathrm{A}$ & $107 / 68 / 13$ & 0.627 & 0.25 \\
$C T N N B 1$ & $\mathrm{rs} 3864004$ & $\mathrm{G} / \mathrm{A}$ & $101 / 73 / 13$ & 0.969 & 0.26 \\
$G S K 3 \beta$ & $\mathrm{rs} 3755557$ & $\mathrm{~T} / \mathrm{A}$ & $131 / 48 / 9$ & 0.106 & 0.18 \\
\hline
\end{tabular}

an the order of wild homozygote / heterozygote / mutant homozygote.

Abbreviations: HWE, Hardy-Weinberg equilibrium; MAF, minor allele frequency.

$P$ value $<0.05$ is shown in bold.

that, compared with the $\mathrm{N}_{0}-\mathrm{N}_{1}$ stage, $\mathrm{N}_{2}-\mathrm{N}_{3}$ stage patients experienced fewer instances of complete remission $(\mathrm{CR})$ for primary tumor $(P=0.048)$ and lymph node $(P=0.009)$, while $M_{1}$ stage patients experienced less incidence of $C R$ for the lymph node $(P=0.049)$ compared with those at $\mathrm{M}_{0}$ stage. Patients treated with RT plus chemotherapy had higher risk of grade 3-4 myelosuppresion than these treated with RT alone. We also found that compared with patients younger than 50 years old, those over age 50 showed more positive results at the lymph node both directly after RT $(P=0.001)$ and 3 months after RT $(P=0.045)$.

\section{Association between selected SNPs of Wnt/ק- catenin pathway genes and the efficacy of RT}

The relationships between the 7 SNPs and the efficacy of RT on lymph nodes were analyzed by PLINK and all positive results are listed in Table 3. CTNNB1 rs1880481 polymorphisms were significantly associated with lower efficacy at the lymph node after RT in the recessive model $(\mathrm{OR}=4.70,95 \% \mathrm{CI}=1.21-18.29$, $P=0.025)$, while no significant difference was found after adjustment for $\mathrm{M}$ stage. After adjustment for age, CTNNB1 rs $1880481(\mathrm{OR}=5.05,95 \% \mathrm{CI}=1.02-25.03$, $P=0.048)$ and $C T N N B 1$ rs3864004 $(\mathrm{OR}=10.50,95 \%$ $\mathrm{CI}=1.03-106.60, P=0.047)$ polymorphisms were strongly related to non-CR at the lymph node 3 months after RT in the recessive model. Patients carrying the minor A allele of CTNNB1 rs1880481 and rs3864004 showed fewer instances of CR (Supplementary Tables S3 - S6)

\section{Stratification analysis of association between selected SNPs in Wnt/ß-catenin pathway genes and the efficacy of RT}

We performed stratification analyses to assess the impacts of these 7 SNPs on the efficacy of RT in NPC patients sorted by age, $\mathrm{N}$ stage, and $\mathrm{M}$ stage. As shown in Table 4, the A allele of CTNNB1 rs1880481 and rs3864004 were significantly related with the lessfavorable efficacy of RT on the primary tumor 3 months after $\mathrm{RT}$ in the allelic, additive and recessive models among patients at the $\mathrm{N}_{0}-\mathrm{N}_{1}$ stage. And CTNNB1 rs1880481 polymorphism was related to non-CR at the lymph node after RT in the recessive model in patients at the $\mathrm{M}_{0}(\mathrm{OR}=5.51,95 \% \mathrm{CI}=1.40-21.77, P=0.015)$ or the $\mathrm{N}_{2}-\mathrm{N}_{3}$ stage $(\mathrm{OR}=4.80,95 \% \mathrm{CI}=1.08-21.37, P=$ $0.040)$ stage. In addition, patients at the $\mathrm{N}_{0}-\mathrm{N}_{1}$ stage with A allele of GSK3 $\beta$ rs3755557 had less incidence of $\mathrm{CR}$ at the lymph node after RT in the allelic $(\mathrm{OR}=7.77,95 \%$ $\mathrm{CI}=1.42-42.58, P=0.007)$ and additive $(\mathrm{OR}=10.65$, $95 \% \mathrm{CI}=1.16-97.44, P=0.036)$ models.

\section{Association between selected SNPs of the Wnt/ $\beta$ - catenin pathway genes and acute grade 3-4 radiation-induced toxic reactions}

The associations between selected 7 SNPs in Wnt/ $\beta$-catenin pathway genes and acute grade 3-4 radiation-induced toxic reactions were calculated by PLINK (Table 5). The GSK3 $\beta$ rs3755557 polymorphism was significantly correlated with the acute grade 3-4 radiation-induced dermatitis in the allelic model $(\mathrm{OR}=2.34,95 \% \mathrm{CI}=1.05-5.21, P=0.033)$. Patients with the minor A allele of rs3755557 were less resistant to acute grade 3-4 radiation-induced dermatitis. The $A P C$ rs454886 polymorphism was significantly associated with acute grade 3-4 radiation-induced oral mucositis in additive $(\mathrm{OR}=1.57,95 \% \mathrm{CI}=1.01-2.43, P=0.045)$ and recessive models $(\mathrm{OR}=2.54,95 \% \mathrm{CI}=1.06-6.13$, $P=0.038$ ) after adjustment for BMI. Individuals carrying the minor A allele of the rs454886 polymorphism had an increased risk of acute grade 3-4 radiation-induced oral mucositis. None of these 7 SNPs in the Wnt/ $\beta$-catenin pathway genes was found to have significant association with acute radiation-induced myelosuppression 
Table 3: Association between CTNNB1 rs1880481 and rs3864004 and the efficacy of RT at the lymph node in NPC patients

\begin{tabular}{|c|c|c|c|c|c|c|c|c|}
\hline \multirow{2}{*}{ Time } & \multirow{2}{*}{ SNP } & \multicolumn{2}{|c|}{ Genotype distribution ${ }^{a}$} & \multirow{2}{*}{ Model } & \multicolumn{2}{|c|}{ Unadjusted } & \multicolumn{2}{|c|}{ Adjusted $^{\mathrm{b}, \mathrm{c}}$} \\
\hline & & Non-CR (MAF) & CR (MAF) & & OR(95\%CI) & $P$ & OR(95\%CI) & $P$ \\
\hline \multirow[t]{4}{*}{ After RT } & rs 1880481 & $4 / 7 / 11$ & $6 / 51 / 76$ & allelic & $1.67(0.84-3.30)$ & 0.141 & - & - \\
\hline & & $(0.34)$ & $(0.24)$ & addictive & $1.67(0.84-3.33)$ & 0.147 & $1.71(0.81-3.60)$ & 0.156 \\
\hline & & & & dominant & $1.33(0.54-3.29)$ & 0.533 & $1.54(0.57-4.22)$ & 0.397 \\
\hline & & & & recessive & $4.70(1.21-18.29)$ & 0.025 & $3.79(0.84-17.17)$ & 0.084 \\
\hline \multirow{8}{*}{$\begin{array}{l}3 \text { months } \\
\text { after RT }\end{array}$} & & $3 / 3 / 6$ & $6 / 36 / 60$ & allelic & $1.95(0.80-4.74)$ & 0.135 & - & - \\
\hline & rs1880481 & $(0.38)$ & $(0.24)$ & addictive & $1.85(0.78-4.36)$ & 0.160 & $1.82(0.76-4.31)$ & 0.177 \\
\hline & & & & dominant & $1.43(0.43-4.74)$ & 0.560 & $1.44(0.43-4.90)$ & 0.555 \\
\hline & & & & recessive & $5.33(1.14-25.01)$ & 0.034 & $5.05(1.02-25.03)$ & 0.048 \\
\hline & rs3864004 & $2 / 4 / 6$ & $3 / 40 / 58$ & allelic & $1.70(0.68-4.21)$ & 0.251 & - & - \\
\hline & & $(0.33)$ & $(0.23)$ & addictive & $1.78(0.68-4.68)$ & 0.240 & $1.73(0.62-4.87)$ & 0.299 \\
\hline & & & & dominant & $1.35(0.41-4.47)$ & 0.625 & $1.19(0.34-4.18)$ & 0.788 \\
\hline & & & & recessive & $6.53(0.97-43.85)$ & 0.053 & $10.50(1.03-106.60)$ & 0.047 \\
\hline
\end{tabular}

an the order of homozygote /heterozygote/ wild type.

${ }^{\mathrm{b}}$ Adjusted for M stage for the association between SNPs and the efficacy of RT at the lymph node.

'Adjusted for age for the association between SNPs and the efficacy of RT at the lymph node 3 months after treatment.

Abbreviations: RT, radiotherapy; CR, complete remission; MAF, minor allele frequency; OR, odds ratio; CI, confidence interval.

$P$ value $<0.05$ is shown in bold.

Table 4: Stratification analysis of association between SNPs in WNT/ß-catenin pathway genes and the efficacy of RT in NPC patients

\begin{tabular}{|c|c|c|c|c|c|c|c|c|c|}
\hline \multirow{2}{*}{ SNPs } & \multirow{2}{*}{$\begin{array}{c}\text { Subgroups } \\
\text { (n) }\end{array}$} & \multirow{2}{*}{$\begin{array}{c}\text { Allelic } \\
\text { OR }(95 \% \text { CI) }\end{array}$} & \multicolumn{3}{|c|}{ Addictive } & \multicolumn{2}{|l|}{ Dominant } & \multicolumn{2}{|l|}{ Recessive } \\
\hline & & & $P$ & OR $(95 \% \mathrm{CI})$ & $P$ & OR $(95 \% \mathrm{CI})$ & $P$ & OR $(95 \% \mathrm{CI})$ & $P$ \\
\hline \multicolumn{10}{|c|}{ At the primary tumor 3 months after treatment } \\
\hline rs1880481 & N0-N1 (63) & $12.91(1.28-129.90)$ & 0.006 & $27.06(1.32-554.60)$ & 0.032 & NA & 0.996 & $60.00(1.99-1805.00)$ & 0.018 \\
\hline rs3864004 & N0-N1 (62) & $10.33(1.03-103.40)$ & 0.016 & $29.75(1.31-675.60)$ & 0.033 & NA & 0.996 & $59.00(1.96-1776.00)$ & 0.019 \\
\hline \multicolumn{10}{|c|}{ At the lymph node after treatment } \\
\hline \multirow[t]{2}{*}{ rs1880481 } & M0 (149) & $1.82(0.89-3.74)$ & 0.097 & $1.83(0.88-3.80)$ & 0.103 & $1.42(0.54-3.74)$ & 0.474 & $5.51(1.40-21.77)$ & 0.015 \\
\hline & N2-N3 (95) & $1.44(0.66-3.12)$ & 0.362 & $1.39(0.66-2.94)$ & 0.386 & $0.95(0.34-2.62)$ & 0.918 & $4.80(1.08-21.37)$ & 0.040 \\
\hline rs3755557 & N0-N1 (60) & $7.77(1.42-42.58)$ & 0.007 & $10.65(1.16-97.44)$ & 0.036 & $6.77(0.57-80.70)$ & 0.131 & NA & 0.999 \\
\hline
\end{tabular}

Abbreviations: OR, odds ratio; CI, confidence interval; NA, not applicable. $P$ value $<0.05$ is shown in bold.

(Supplementary Table S9). And none of the 7 SNPs was found significantly associated with 3 kinds of acute radiation-induced toxic reaction in stratification analyses.

\section{DISCUSSION}

Emerging evidence has revealed that $\beta$-catenin plays an oncogenic role in the regulations of proliferation, differentiation, development and tissue regeneration, and also functions as a transcriptional co-activator of the Wnt/ $\beta$-catenin pathway [39-42]. For instance, the tumor growth of NPC was markedly attenuated when the expression of CTNNB1 was suppressed, which indicated that $\beta$-catenin may play an important oncogenic role in the migration and proliferation of NPC cells [33]. Importantly, genetic variants in the $\mathrm{Wnt} / \beta$-catenin pathway could be predictors of cancer risk in multiple human malignancies [43-48]. In this study, we examined the association of 7 SNPs in the Wnt/ $\beta$-catenin pathway genes and the efficacy and radiation-induced toxic reactions in 188 NPC patients treated with RT (with or without chemotherapy). Our results showed that 3 SNPs (CTNNB1 rs1880481 and rs3864004, and GSK3 $\beta$ rs375557) were correlated to the efficacy of RT, and 2 SNPs (APC rs454886 and GSK3 $\beta$ rs375557) were correlated with acute grade 3-4 radiationinduced toxic reactions in NPC patients. 
Table 5: Association between GSK3 $\beta$ rs3755557 and $A P C$ rs454886 and the acute grade 3-4 radiation-induced toxic reactions

\begin{tabular}{|c|c|c|c|c|c|c|c|c|}
\hline \multirow{2}{*}{$\begin{array}{l}\text { Radiation-induced toxic } \\
\text { reactions }\end{array}$} & \multirow{2}{*}{ SNP } & \multicolumn{2}{|c|}{ Genotype distribution ${ }^{\mathrm{a}}$} & \multirow{2}{*}{ Model } & \multicolumn{2}{|c|}{ unadjusted } & \multicolumn{2}{|c|}{ Adjusted $^{\mathrm{b}}$} \\
\hline & & Grade 3-4 (MAF) & Grade 0-2 (MAF) & & OR $(95 \% \mathrm{CI})$ & $P$ & OR $(95 \% \mathrm{CI})$ & $P$ \\
\hline \multirow[t]{4}{*}{$\begin{array}{l}\text { Grade 3-4 } \\
\text { dermatitis }\end{array}$} & rs 3755557 & $2 / 6 / 8$ & $7 / 42 / 123$ & allelic & $2.34(1.05-5.21)$ & 0.033 & - & - \\
\hline & & $(0.31)$ & $(0.16)$ & addictive & $2.13(1.00-4.55)$ & 0.051 & - & - \\
\hline & & & & dominant & $2.51(0.89-7.06)$ & 0.081 & - & - \\
\hline & & & & recessive & $3.37(0.64-17.77)$ & 0.153 & - & - \\
\hline \multirow[t]{4}{*}{$\begin{array}{c}\text { Grade } 3-4 \\
\text { oral mucositis }\end{array}$} & rs 454886 & $17 / 43 / 29$ & $9 / 49 / 41$ & allelic & $1.49((0.98-2.26)$ & 0.061 & - & - \\
\hline & & $(0.43)$ & $(0.34)$ & addictive & $1.52(0.99-2.34)$ & 0.058 & $1.57(1.01-2.43)$ & 0.045 \\
\hline & & & & dominant & $1.46(0.81-2.66)$ & 0.212 & $1.50(0.82-2.73)$ & 0.191 \\
\hline & & & & recessive & $2.36(0.99-5.61)$ & 0.052 & $2.54(1.06-6.13)$ & 0.038 \\
\hline
\end{tabular}

an the order of wild homozygote /heterozygote/ wild type.

${ }^{\mathrm{b}}$ Adjusted for BMI.

Abbreviations: MAF, minor allele frequency; OR, odds ratio; CI, confidence interval; $P$ value $<0.05$ is shown in bold.

In the present study, the results of logistic regression indicated that patients with the minor A allele of CTNNB1 rs1880481 and rs3864004 polymorphisms obtained less favorable outcomes with RT in NPC. Since the rs 1880481 was identified in the intron region of $C T N N B 1$, it may up-regulate the expression $\beta$-catenin by affecting the mRNA splicing, localization and stability [49]. Another conceivable mechanism is that the real functional variant mediating this process is not the SNP rs1880481 but another variant in linkage disequilibrium (LD) with it [50]. To our knowledge, there has no report about the correlation of rs1880481 polymorphism and development and prognosis of NPC. Without a doubt, more studies about the rs 1880481 and potential functional polymorphism sites in $\mathrm{LD}$ are requisite to verify the exact mechanism. The rs3864004 was located in the promoter region of the CTNNB1 and its polymorphism has been reported to be associated with development and survival of hepatocellular carcinoma [51]. Consistent with this, we found that CTNNB1 rs3864004 was significantly related with poorer efficacy at lymph node after RT in $\mathrm{NPC}$ patients (AA $v s \mathrm{AG}+\mathrm{GG}$ : $\mathrm{aOR}=10.50, P=0.047$ ). Moreover, our results showed that CTNNB1 rs3864004 was also associated with the efficacy at primary tumor in NPC patients at $\mathrm{N}_{0}-\mathrm{N}_{1}$ stage. Along with previous study [31], our findings indicated that rs3864004 polymorphism may stimulate $\beta$-catenin expression and lead to the accumulation of $\beta$-catenin, which could subsequently promote the proliferation of NPC cells and weakens the efficacy of RT.

GSK3 $\beta$ is a crucial regulatory kinase interacting with multiple pathways in addition to the Wnt/ $\beta$-catenin pathway, which controls various physiological processes such as neurodevelopment and cellular differentiation, proliferation, survival, and apoptosis $[52,53]$. The results of subgroup analyses showed that GSK3 $\beta$ rs3755557 was associated with reduced efficacy of RT at the lymph node in the allelic $(\mathrm{OR}=7.77, P=0.007)$ and additive $(\mathrm{OR}=10.65, P=0.036)$ models in the $\mathrm{N}_{0}-\mathrm{N}_{1}$ stage patients. Moreover, the A allele of GSK3 3 rs 3755557 was also correlated to increased risk of grade 3-4 radiationinduced dermatitis compared with $\mathrm{T}$ allele $(\mathrm{OR}=2.34$, $P=0.033)$ in our study. These results suggested that the polymorphism of GSK3 $\beta$ rs3755557 may inhibit the expression of GSK3 $\beta$, leading to the aggregation of $\beta$-catenin, the activation of $\mathrm{Wnt} / \beta$-catenin signaling, and higher resistance to RT. Our study is the first time to show a relationship between GSK3 $\beta$ rs3755557 and radiationinduced dermatitis, but further investigation is needed to delineate the precise mechanism. As a tumor suppressor, APC protects $\beta$-catenin from dephosphorylation and enhances $\beta$-catenin degradation. Wang et al. reported that the rs454886 polymorphism in $A P C$ was strongly correlated to an increased risk of breast cancer [54]. We also found that $A P C$ rs454886 was associated with acute grade 3-4 radiation-induced oral mucositis in the additive $(\mathrm{OR}=1.57, P=0.045)$ and recessive $(\mathrm{OR}=2.54$, $P=0.038$ ) models after adjustment. Further studies are required to elucidate this association between $A P C$ and radiation-induced toxic reaction in NPC.

The advantage of our study lies in the fact that it is the first time to explore the impact of SNPs in genes of the Wnt/ $\beta$-catenin pathway on the curative efficacy of RT, as well as on radiation-induced toxic reactions in NPC patients. However, one limitation of this study was its sample size, particularly in relation to our stratification analysis. Therefore, replication studies are required to validate our results in more independent subjects. In conclusion, we found that CTNNB1 rs1880481, CTNNB1 rs3864004, and GSK3B rs375557 were correlative with the curative efficacy of RT, and that GSK3 $\beta$ rs 375557 and $A P C$ rs 454886 were correlative with acute grade 3-4 
radiation-induced dermatitis and oral mucositis. These SNPs may be potential prognostic markers for NPC patients treated with RT.

\section{MATERIALS AND METHODS}

\section{Patient selection}

The present study's protocol was approved by the ethics committee of the Cancer Hospital of Jiangxi Province (China) and registered online through the website of the Chinese Clinical Trial Registry (www.chictr.org.cn, registration number: ChiCTROPC-14005257). All eligible patients signed informed consent before participating in this study. The study initially approached 236 NPC patients treated with RT in the Cancer Hospital of Jiangxi Province between April 2014 and September 2015. Patients were enrolled if they met the following criteria: a diagnosis of NPC; performance status score $\leqq 1$; no severe disorders of heart, lung, liver or kidney; and no prior treatment with other anticancer therapies before undergoing radiotherapy or chemotherapy, $\geqq 1$ measurable lesions. The exclusion criteria were: active infection, pregnancy or lactation, previous or concomitant malignancies and absence of any follow-up. We recorded the demographics and clinical data of enrolled patients including age, gender, and smoking and drinking habits, TNM (7th UICC) stage and comorbidities. Ultimately, 188 patients were included in the study and its subsequent statistical analysis.

\section{Efficacy regimen}

A total of 38 patients were treated with RT alone and the remaining 150 were treated with RT and chemotherapy. All patients were treated with intensitymodulated radiation-therapy (IMRT) technique. The prescribed dosage of radiation therapy was $66-70 \mathrm{~Gy}$ in $30-33$ fractions for nasopharyngeal primary focus and the cervical positive lymph nodes and $54-60$ Gy in $30-33$ fractions for cervical drainage region, respectively. One fraction was performed daily and five fractions weekly. Induction chemotherapy and concurrent chemotherapy were all performed with platinum-based chemotherapy regimens.

\section{Evaluations of efficacy and toxic reactions}

All patients underwent magnetic resonance imaging (MRI) directly after treatment and 3 months later after treatment. Treatment efficacies at the primary tumor and lymph node were evaluated in line with the response evaluation criteria in solid tumors (RECIST) by the World Health Organization (WHO). RECIST defines treatment efficacy, based on tumor volume, as: complete remission $(\mathrm{CR})$, partial remission (PR), stable disease (SD), and progression disease (PD). In this study we subdivided the subjects into two groups: CR and non-CR (consisting of PR, SD and PD).

Acute radiation-induced toxic reactions including dermatitis, oral mucositis and myelosuppression were recorded and evaluated according to the acute radiation toxicity grading criteria of the Radiation Therapy Oncology Group or European Organization for Research and Efficacy of Cancer (RTOG/EORTC). For each toxic reaction, patients were subdivided into a 'non-sensitive or mildly radiosensitive' group (grade 0-2) and a 'highly radiosensitive' group (grade 3-4). All acute toxic reactions were observed once a day from the first day to the end of RT.

\section{DNA extraction and genotyping assays}

Peripheral blood samples of $3 \mathrm{~mL}$ were taken before radiotherapy and stored in EDTA anti-coagulative tubes at $-20^{\circ} \mathrm{C}$. Genetic DNA of all patients was extracted using Wizard Genomic DNA Purification Kit (Promega, Madison, USA). The genotyping for 9 SNPs of the Wnt/ $\beta$-catenin pathway genes was conducted by Sequenom MassARRAY system (Sequenom, San Diego, California, USA). Primers were designed by using Assay Designer 3.1 and the details about primer sequence for each SNP site were listed in Supplementary Table S10. The polymerase chain reaction (PCR) scheme was defined by an initial denaturation at $94^{\circ} \mathrm{C}$ for $15 \mathrm{~min}$, followed by 45 cycles for $20 \mathrm{~s}$ at $94^{\circ} \mathrm{C}, 30 \mathrm{~s}$ at $56^{\circ} \mathrm{C}, 1 \mathrm{~min}$ at $72^{\circ} \mathrm{C}$, with a final elongation at $72^{\circ} \mathrm{C}$ for $3 \mathrm{~min}$. The products of PCR were purified in shrimp alkaline phosphatase (SAP), which was performed by incubating at $37^{\circ} \mathrm{C}$ for $40 \mathrm{~min}$, followed by $85^{\circ} \mathrm{C}$ for $5 \mathrm{~min}$. A extension reaction was performed using extension primers and the extension products were desalted by the addition of a cation exchange resin. The desalination products were centrifuged at 4000r for $4 \mathrm{~min}$ before transferred in CHIP. Data from CHIP was analyzed by Typer Analyzer.

\section{Statistical analysis}

Deviations from Hardy-Weinberg equilibrium were calculated using $\chi 2$ analysis. Univariate logistic regression was performed to determine the association of each SNP of $A P C, W N T 2, C T N N B 1$, and $G S K 3 B$ with the curative efficacy at the primary tumor and lymph node. Likewise, the association between these 9 SNPs and the indicators for high radiosensitivity such as dermatitis, oral mucositis, and myelosuppression grade 3-4 was calculated by univariate logistic regression. The chi-square test was used to determine the associations between the two alleles of each SNP and the efficacy and toxic reaction.

Continuous variables such as age and BMI were switched to binary variables. The effects of clinical factors such as sex, age, BMI, TNM cancer stage (UJCC), smoking and drinking habits, family history, and receipt 
or lack of chemotherapy on efficacy and toxic reactions were computed using chi-square test, separately. Only those factors with a $P$ value $<0.1$ in the chi-square test were considered to be adjusted factors warranted further multivariate analysis. Subsequently, multivariate logistic regression was carried out to evaluate the effect of each SNP on non-CR at the primary tumor and lymph node as well as grade 3-4 dermatitis, oral mucositis, and myelosuppression, by computing the odds ratio (OR) and the corresponding $95 \%$ confidence interval $(\mathrm{CI})$, with $\mathrm{CR}$ at the primary tumor and lymph node as well as grade 0-2 dermatitis, oral mucositis, and myelosuppression as the reference, respectively. In addition, stratification analyses were performed to characterize the associations between SNPs and RT efficacy and toxic reactions in some subgroups when the corresponding clinical factor had $P$ value $<0.1$ in the chi-square test. The difference was considered statistically significant when the $P$ value $<0.05$. All aforementioned statistical analyses were performed by SPSS18.0 (IBM, Armonk, New York, USA) and PLINK 1.07 (http://pngu.mgh.harvard.edu/ purcell/plink/).

\section{ACKNOWLEDGMENTS AND FUNDING}

This research was supported by the National Natural Science Foundation of China (81460409 and 81301924), the Natural Science Foundation of Hunan (14JJ7016), Scientific and Technological Project of Hunan (2015RS4010), the Scientific and Technological Project of Hunan Health and Family Planning Commission (B2015-33), the Scientific and Technological Project of Changsha (k1403065-31), the New Xiangya Talent Project of the Third Xiangya Hospital of Central South University (JY201505), and the Independent Exploration and Innovation Project for Postgraduate of Central South University (2016zzts564).

\section{CONFLICTS OF INTEREST}

The authors claim that no conflicts of interest exist.

\section{REFRENCES}

1. Siegel RL, Miller KD, Jemal A. Cancer statistics, 2016. CA Cancer J Clin. 2016; 66:7-30.

2. Kamran SC, Riaz N, Lee N. Nasopharyngeal carcinoma. Surg Oncol Clin N Am. 2015; 24:547-561.

3. Wang M, Tian H, Li G, Ge T, Liu Y, Cui J, Han F. Significant benefits of adding neoadjuvant chemotherapy before concurrent chemoradiotherapy for locoregionally advanced nasopharyngeal carcinoma: a meta-analysis of randomized controlled trials. Oncotarget. 2016; 7:48375-48390. doi: 10.18632/oncotarget.10237.

4. Trotti A. Toxicity in head and neck cancer: a review of trends and issues. Int J Radiat Oncol Biol Phys. 2000; 47:1-12.
5. Cheuk IW, Yip SP, Kwong DL, Wu VW. Association of XRCC1 and XRCC3 gene haplotypes with the development of radiation-induced fibrosis in patients with nasopharyngeal carcinoma. Mol Clin Oncol. 2014; 2:553-558.

6. Guo Z, Shu Y, Zhou H, Zhang W, Wang H. Radiogenomics helps to achieve personalized therapy by evaluating patient responses to radiation treatment. Carcinogenesis. 2015; 36:307-317.

7. Kerns SL, Ostrer H, Rosenstein BS. Radiogenomics: using genetics to identify cancer patients at risk for development of adverse effects following radiotherapy. Cancer Discov. 2014; 4:155-165.

8. Li SS, Tang QL, Wang SH, Wang S, Yang XM. Simultaneously targeting bcl-2 and Akt pathways sensitizes nasopharyngeal carcinoma to tumor necrosis factor-related apoptosis-inducing ligand. Cancer Biother Radiopharm. 2012; 27:88-95.

9. Wang YP, Lin CF, Tsai SC, Tsai CH, Yeh TH. Upregulation of Caveolin-1 correlate with Akt expression and poor prognosis in NPC patients. Laryngoscope. 2015; 125:E231-238.

10. Zou Y, Song T, Yu W, Zhao R, Wang Y, Xie R, Chen T, $\mathrm{Wu} \mathrm{B}, \mathrm{Wu} \mathrm{S}$. XRCC3 polymorphisms are associated with the risk of developing radiation-induced late xerostomia in nasopharyngeal carcinoma patients treated with intensity modulation radiated therapy. Jpn J Clin Oncol. 2014; 44:241-248.

11. Shaw V, Bullock K, Greenhalf W. Single-Nucleotide Polymorphism to Associate Cancer Risk. Methods Mol Biol. 2016; 1381:93-110.

12. Srinivasan S, Clements JA, Batra J. Single nucleotide polymorphisms in clinics: Fantasy or reality for cancer? Crit Rev Clin Lab Sci. 2016; 53:29-39.

13. Gibbs DC, Orlow I, Bramson JI, Kanetsky PA, Luo L, Kricker A, Armstrong BK, Anton-Culver H, Gruber SB, Marrett LD, Gallagher RP, Zanetti R, Rosso S, et al. Association of Interferon Regulatory Factor-4 Polymorphism rs12203592 With Divergent Melanoma Pathways. J Natl Cancer Inst. 2016; 108.

14. Liu Y, Xu SN, Chen YS, Wu XY, Qiao L, Li K, Yuan L. Study of single nucleotide polymorphisms of FBW7 and its substrate genes revealed a predictive factor for paclitaxel plus cisplatin chemotherapy in Chinese patients with advanced esophageal squamous cell carcinoma. Oncotarget. 2016; 7:44330-39. doi: 10.18632/oncotarget.9736.

15. Schirmer MA, Luske CM, Roppel S, Schaudinn A, Zimmer C, Pfluger R, Haubrock M, Rapp J, Gungor C, Bockhorn M, Hackert T, Hank T, Strobel O, et al. Relevance of Sp Binding Site Polymorphism in WWOX for Treatment Outcome in Pancreatic Cancer. J Natl Cancer Inst. 2016; 108.

16. Li H, You Y, Lin C, Zheng M, Hong C, Chen J, Li D, Au WW, Chen Z. XRCC1 codon 399Gln polymorphism is associated with radiotherapy-induced acute dermatitis and mucositis in nasopharyngeal carcinoma patients. Radiat Oncol. 2013; 8:31. 
17. Liu B, Yi M, Tang Y, Liu Q, Qiu H, Zou Y, Peng P, Zhang L, Hu C, Yuan X. MMP-1 promoter polymorphism is associated with risk of radiation-induced lung injury in lung cancer patients treated with radiotherapy. Oncotarget. 2016; 7:70175-84. doi: 10.18632/oncotarget.12164.

18. MacDonald BT, Tamai K, He X. Wnt/beta-catenin signaling: components, mechanisms, and diseases. Dev Cell. 2009; 17:9-26.

19. Zhan T, Rindtorff N, Boutros M. Wnt signaling in cancer. Oncogene. 2016.

20. Reya T, Clevers H. Wnt signalling in stem cells and cancer. Nature. 2005; 434:843-850.

21. Baarsma HA, Konigshoff M, Gosens R. The WNT signaling pathway from ligand secretion to gene transcription: molecular mechanisms and pharmacological targets. Pharmacol Ther. 2013; 138:66-83.

22. Elghazi L, Gould AP, Weiss AJ, Barker DJ, Callaghan J, Opland D, Myers M, Cras-Meneur C, Bernal-Mizrachi E. Importance of beta-Catenin in glucose and energy homeostasis. Sci Rep. 2012; 2:693.

23. Guan Z, Zhang J, Wang J, Wang H, Zheng F, Peng J, Xu Y, Yan M, Liu B, Cui B, Huang Y, Liu Q. SOX1 downregulates beta-catenin and reverses malignant phenotype in nasopharyngeal carcinoma. Mol Cancer. 2014; 13:257.

24. Paez D, Gerger A, Zhang W, Yang D, Labonte MJ, Benhanim L, Kahn M, Lenz F, Lenz C, Ning Y, Wakatsuki T, Loupakis F, Lenz HJ. Association of common gene variants in the WNT/beta-catenin pathway with colon cancer recurrence. Pharmacogenomics J. 2014; 14:142-150.

25. Sherwood V. WNT signaling: an emerging mediator of cancer cell metabolism? Mol Cell Biol. 2015; 35:2-10.

26. Anastas JN, Moon RT. WNT signalling pathways as therapeutic targets in cancer. Nat Rev Cancer. 2013; 13:11-26.

27. Jiang H, Li Q, He C, Li F, Sheng H, Shen X, Zhang X, Zhu S, Chen H, Chen X, Yang C, Gao H. Activation of the Wnt pathway through Wnt2 promotes metastasis in pancreatic cancer. Am J Cancer Res. 2014; 4:537-544.

28. Cojoc M, Peitzsch C, Kurth I, Trautmann F, KunzSchughart LA, Telegeev GD, Stakhovsky EA, Walker JR, Simin K, Lyle S, Fuessel S, Erdmann K, Wirth MP, et al. Aldehyde Dehydrogenase Is Regulated by beta-Catenin/ TCF and Promotes Radioresistance in Prostate Cancer Progenitor Cells. Cancer Res. 2015; 75:1482-1494.

29. Gomez-Millan J, Perez L, Aroca I, Del Mar Delgado M, De Luque V, Roman A, Torres E, Ramos S, Perez S, Bayo E, Medina JA. Preoperative chemoradiotherapy in rectal cancer induces changes in the expression of nuclear beta-catenin: prognostic significance. BMC Cancer. 2014; 14:192.

30. Hai B, Yang Z, Shangguan L, Zhao Y, Boyer A, Liu F. Concurrent transient activation of Wnt/beta-catenin pathway prevents radiation damage to salivary glands. Int J Radiat Oncol Biol Phys. 2012; 83:e109-116.

31. Bae S, Lee H, Choi BW, Lee HK, Chung SI, Kim W, Kim K, Seo SJ, Kim DS, Kim SM, Yoon Y. Beta-catenin promoter polymorphism is associated with asthma risk in Korean subjects. Clin Biochem. 2012; 45:1187-1191.
32. Butrym A, Rybka J, Lacina P, Gebura K, Frontkiewicz D, Bogunia-Kubik K, Mazur G. Polymorphisms within beta-catenin encoding gene affect multiple myeloma development and treatment. Leuk Res. 2015; 39:1462-1466.

33. Jiang R, Niu X, Huang Y, Wang X. beta-Catenin is important for cancer stem cell generation and tumorigenic activity in nasopharyngeal carcinoma. Acta Biochim Biophys Sin (Shanghai). 2016; 48:229-237.

34. Lee JY, Park AK, Lee KM, Park SK, Han S, Han W, Noh DY, Yoo KY, Kim H, Chanock SJ, Rothman N, Kang D. Candidate gene approach evaluates association between innate immunity genes and breast cancer risk in Korean women. Carcinogenesis. 2009; 30:1528-1531.

35. Starinsky S, Figer A, Ben-Asher E, Geva R, Flex D, Fidder HH, Zidan J, Lancet D, Friedman E. Genotype phenotype correlations in Israeli colorectal cancer patients. Int J Cancer. 2005; 114:58-73.

36. Wang S, Tian Y, Wu D, Zhu H, Luo D, Gong W, Zhou Y, Zhou J, Zhang Z. Genetic variation of CTNNB1 gene is associated with susceptibility and prognosis of gastric cancer in a Chinese population. Mutagenesis. 2012; 27:623-630.

37. Xu Y, Li H, Huang C, Zhao T, Zhang H, Zheng C, Ren H, Hao J. Wnt2 protein plays a role in the progression of pancreatic cancer promoted by pancreatic stellate cells. Med Oncol. 2015; 32:97.

38. Yadav A, Gupta A, Yadav S, Rastogi N, Agrawal S, Kumar A, Kumar V, Misra S, Mittal B. Association of Wnt signaling pathway genetic variants in gallbladder cancer susceptibility and survival. Tumour Biol. 2016; 37:8083-8095.

39. Ren XY, Zhou GQ, Jiang W, Sun Y, Xu YF, Li YQ, Tang XR, Wen X, He QM, Yang XJ, Liu N, Ma J. Low SFRP1 Expression Correlates with Poor Prognosis and Promotes Cell Invasion by Activating the Wnt/beta-Catenin Signaling Pathway in NPC. Cancer Prev Res (Phila). 2015; 8:968-977.

40. Cheng Y, Phoon YP, Jin X, Chong SY, Ip JC, Wong BW, Lung ML. Wnt-C59 arrests stemness and suppresses growth of nasopharyngeal carcinoma in mice by inhibiting the Wnt pathway in the tumor microenvironment. Oncotarget. 2015; 6:14428-14439. doi: 10.18632/oncotarget.3982.

41. Zong D, Yin L, Zhong Q, Guo WJ, Xu JH, Jiang N, Lin ZR, Li MZ, Han P, Xu L, He X, Zeng MS. ZNF488 Enhances the Invasion and Tumorigenesis in Nasopharyngeal Carcinoma Via the Wnt Signaling Pathway Involving Epithelial Mesenchymal Transition. Cancer Res Treat. 2016; 48:334-344.

42. Xu L, Jiang Y, Zheng J, Xie G, Li J, Shi L, Fan S. Aberrant expression of beta-catenin and E-cadherin is correlated with poor prognosis of nasopharyngeal cancer. Hum Pathol. 2013; 44:1357-1364.

43. Hildebrandt MA, Reyes ME, Lin M, He Y, Nguyen SV, Hawk ET, Wu X. Germline Genetic Variants in the Wnt/betaCatenin Pathway as Predictors of Colorectal Cancer Risk. Cancer Epidemiol Biomarkers Prev. 2016; 25:540-546. 
44. Pierzynski JA, Hildebrandt MA, Kamat AM, Lin J, Ye Y, Dinney CP, Wu X. Genetic Variants in the Wnt/beta-Catenin Signaling Pathway as Indicators of Bladder Cancer Risk. J Urol. 2015; 194:1771-1776.

45. Mostowska A, Pawlik P, Sajdak S, Markowska J, Pawalowska M, Lianeri M, Jagodzinski PP. An analysis of polymorphisms within the Wnt signaling pathway in relation to ovarian cancer risk in a Polish population. Mol Diagn Ther. 2014; 18:85-91.

46. Alanazi MS, Parine NR, Shaik JP, Alabdulkarim HA, Ajaj SA, Khan Z. Association of single nucleotide polymorphisms in Wnt signaling pathway genes with breast cancer in Saudi patients. PLoS One. 2013; 8:e59555.

47. Ting WC, Chen LM, Pao JB, Yang YP, You BJ, Chang TY, Lan YH, Lee HZ, Bao BY. Common genetic variants in Wnt signaling pathway genes as potential prognostic biomarkers for colorectal cancer. PLoS One. 2013; 8:e56196.

48. Hirata H, Hinoda Y, Nakajima K, Kikuno N, Yamamura S, Kawakami K, Suehiro Y, Tabatabai ZL, Ishii N, Dahiya R. Wnt antagonist gene polymorphisms and renal cancer. Cancer. 2009; 115:4488-4503.

49. Modrek B, Resch A, Grasso C, Lee C. Genome-wide detection of alternative splicing in expressed sequences of human genes. Nucleic Acids Res. 2001; 29:2850-2859.

50. Wang M, Yuan L, Wu D, Zhang Z, Yin C, Fu G, Wei Q. A novel XPF -357A $>$ C polymorphism predicts risk and recurrence of bladder cancer. Oncogene. 2010; 29:1920-1928.
51. Kim SS, Cho HJ, Lee HY, Park JH, Noh CK, Shin SJ, Lee KM, Yoo BM, Lee KJ, Cho SW, Cheong JY. Genetic polymorphisms in the $\mathrm{Wnt} /$ beta-catenin pathway genes as predictors of tumor development and survival in patients with hepatitis B virus-associated hepatocellular carcinoma. Clin Biochem. 2016; 49:792-801.

52. Li M, Mo Y, Luo XJ, Xiao X, Shi L, Peng YM, Qi XB, Liu XY, Yin LD, Diao HB, Su B. Genetic association and identification of a functional SNP at GSK3beta for schizophrenia susceptibility. Schizophr Res. 2011; 133:165-171.

53. McCubrey JA, Steelman LS, Bertrand FE, Davis NM, Abrams SL, Montalto G, D'Assoro AB, Libra M, Nicoletti F, Maestro R, Basecke J, Cocco L, Cervello M, et al. Multifaceted roles of GSK-3 and Wnt/beta-catenin in hematopoiesis and leukemogenesis: opportunities for therapeutic intervention. Leukemia. 2014; 28:15-33.

54. Wang X, Goode EL, Fredericksen ZS, Vierkant RA, Pankratz VS, Liu-Mares W, Rider DN, Vachon CM, Cerhan JR, Olson JE, Couch FJ. Association of genetic variation in genes implicated in the beta-catenin destruction complex with risk of breast cancer. Cancer Epidemiol Biomarkers Prev. 2008; 17:2101-2108. 